\title{
Hyper-Elongation in Colorectal Cancer Tissue - Cerotic Acid is a Potential Novel Serum Metabolic Marker of Colorectal Malignancies
}

\author{
Adriana Mika ${ }^{a, b}$ Jaroslaw Kobielac Aleksandra Czumaj ${ }^{b}$ Michał Chmielewskid \\ Piotr Stepnowskia Tomasz Sledzinskib \\ aDepartment of Environmental Analysis, Faculty of Chemistry, University of Gdansk, Gdansk, \\ bDepartment of Pharmaceutical Biochemistry, Medical University of Gdansk, Gdansk, 'Department of \\ General, Endocrine and Transplant Surgery, Medical University of Gdansk, Gdansk, 'Department of \\ Nephrology, Transplantology and Internal Medicine, Medical University of Gdansk, Gdansk, Poland
}

\section{Key Words}

Colorectal cancer $\bullet$ Cerotic acid $•$ Colon mucosa $•$ Elongase $•$ Fatty acids $•$ Gas chromatographymass spectrometry $\cdot$ Serum

\begin{abstract}
Backgrounds/Aims: Colorectal cancer (CRC) cells show some alterations of lipid metabolism. Elongation of fatty acids (FA) has not been studied in CRC tissues thus far. The aim of this study was to verify if CRC specimens and normal colon mucosa differ in terms of their levels of very long-chain FAs, a product of FA elongation. Moreover, the expression of elongase genes has been studied in normal tissue and CRC. Finally, we searched for some specific products of FA elongation in serum of CRC patients. Methods: The specimens of normal colon mucosa and CRC were obtained from nineteen CRC patients differ in terms of FA elongation. We also searched for some specific products of FA elongation in serum of CRC patients and from healthy volunteers. Tissue and serum FA profiles were determined by means of gas chromatographymass spectrometry (GC/MS), and the tissue expression of elongases (ELOVLs) was analyzed with real-time PCR. Results: Compared to normal colon tissue, CRC specimens showed significantly higher levels of 22-, 24- and 26-carbon FAs, stronger expressions of ELOVL1 and ELOVL6 (4- and 9-fold elevated respectively), and higher values of 18:0/16:0 elongation index. We also demonstrated presence of cerotic acid (26:0) in serum of all CRC patients but in none of the healthy controls. Conclusions: CRC tissue seems to be characterized by enhanced FA elongation (hyper-elongation). Presence of cerotic acid in CRC patients sera and absence of this FA in healthy subjects points to this compound as a strong candidate for specific metabolic marker of colorectal malignancies.
\end{abstract}

Introduction

(c) 2017 The Author(s)

Published by S. Karger AG, Basel

Colorectal cancer (CRC) is the second leading cause of mortality among oncological patients. Despite a progress in surgical technique, chemotherapy and radiotherapy, still new 
diagnostic and prognostic markers of CRC and novel therapeutic targets are needed. Development of efficient diagnostic and therapeutic strategies requires complete understanding of CRC pathophysiology. Recent research revealed an important role of microRNAs in CRC development and progression [1,2]. Lipidome, i.e. the sum of all lipids, related enzymes, receptors and signaling pathways, plays a key role in many cellular processes, such as metabolism, energy storage, proliferation and apoptosis. Besides the environmental and genetic risk factors including telomere length $[3,4]$ also the dysregulation of lipid metabolism and function is known to contribute to CRC development, and it may potentially serve as a therapeutic and prognostic marker in patients with this malignancy [5].

Carcinogenesis is associated with substantial changes in cellular metabolism, including alterations of lipid, carbohydrate, nucleic acid and amino acid metabolism [6]. These changes promote rapid proliferation of cancer cells. Already more than eight decades ago, Warburg demonstrated that enhanced aerobic glycolysis, a phenomenon commonly referred to as the Warburg effect, is a distinctive feature of many human and animal malignancies [6]. During the course of glycolysis, glucose may be transformed into lactate or acetyl-CoA, a substrate for the synthesis of fatty acids (FAs) and cholesterol. FAs of phospholipids and cholesterol are the principal component of plasma membranes, which makes them vitally important substrate for rapidly proliferating cancer cells. Interestingly, Zaytseva et al. [7] demonstrated that overexpression of fatty acid synthase (FASN), the main enzyme involved in FA synthesis, plays a key role in maintaining energy homeostasis of CRC cells via increased oxidation of endogenous lipids. Furthermore, FAs serve as a substrate for protein palmitoylation, a key process involved in regulation of cancer cell proliferation [6]. Elevated activity of enzymes involved in the synthesis of lipids (FAs and cholesterol) was documented in many types of cancer $[6,8]$. Also the oxidation of FAs has been identified as an important determinant of cancer cell function $[7,9]$.

FA elongases (ELOVLs) can be divided into two groups: ELOVLs 1, 3 and 6, involved in the elongation of saturated FAs (SFAs) and monounsaturated FAs (MUFAs), and ELOVLs 2, 4 and 5, responsible for the processing of polyunsaturated FAs (PUFAs) [10]. ELOVL6 is the main enzyme of elongase family, playing an established role in energy metabolism and development of insulin sensitivity [11]. Recently, Marien et al. [12] demonstrated that an increase in acyl chain length in lung cancer tissue of human and mouse is associated with significantly elevated expression of acyl chain elongases, especially ELOVL6. Inhibition of ELOVL6 was shown to significantly reduce the proliferation of squamous cell carcinoma (SCC) cell lines in vitro and to attenuate their growth as a xenograft in an in vivo mouse model [12]. However, to the best of our knowledge, none of the previous studies analyzed FA elongation in CRC tissue. Therefore, the aim of this study was to verify if CRC tissue contains elongated FA acyl chains and shows elevated expression and activity of ELOVLs. Moreover, we searched for specific products of FA elongation in the blood of CRC patients.

\section{Materials and Methods}

\section{Patients}

The study included tissue samples from nineteen patients with stage I-III CRC (mean age $=73 \pm 9.8$ years), obtained from surgical specimens immediately after resection thereof. Detailed characteristics of the study subjects are presented in Table 1 . None of the patients received neoadjuvant treatment prior to the surgery. Tissue samples were collected both from the tumor and from normal large intestinal mucosa, $5 \mathrm{~cm}$ from the tumor interface. Each sample was divided in two parts: one was used for molecular analysis and another one for preparation of routine H\&E stained microscopic slides for histopathological examination. The material for molecular studies was frozen in liquid nitrogen immediately after collection and stored in aliquots at $-80^{\circ} \mathrm{C}$ until analysis. Moreover, 5-ml blood samples were collected from all CRC patients and from seventeen healthy volunteers (10 male/ 7 female, mean age $=62 \pm 8.4$ years, mean $\mathrm{BMI}=27$ $\pm 3.2 \mathrm{~kg} / \mathrm{m}^{2}$ ) with similar demographic and socioeconomic characteristics, who have been referred to an annual medical check-up. Fasting blood samples were collected to the tubes without anticoagulant, kept at 


\section{Cellular Physiology Cell Physiol Biochem 2017;41:722-730 \begin{tabular}{ll|l} 
and Biochemistry & $\begin{array}{l}\text { DOI 10.1159/000458431 } \\
\text { Published onlne: February 08, } 2017\end{array}$ & $\begin{array}{l}\text { 2017 The Author(s). Published by S. Karger AG, Basel } \\
\text { www. arger.com/cpb }\end{array}$ \\
\cline { 2 - 3 }
\end{tabular} \\ Mika et al.: Hyper-Elongation in Colorectal Cancer}

Table 1. Demographic and clinical data of the patients

\begin{tabular}{llllllll}
\hline Case & Localisation (ICD-10) & Sex & Age & BMI & pTNM stage & Grade & Hypolipidemic drugs \\
\hline 1 & Ascending colon (C18.2) & M & 76 & 24 & pT3N0M0 & G3 & no \\
2 & Sigmoid colon (C18.7) & M & 79 & 24 & pT3N1bM0 & G2 & no \\
3 & Rectosigomid junction (C19) & M & 71 & 32 & pT4aN1bM0 & G2 & rosuvastatinum \\
4 & Hepatic flexure (C18.3) & M & 84 & 25 & pT2N0M0 & G2 & no \\
5 & Ascending colon (C18.2) & M & 67 & 38 & pT2N0M0 & G2 & no \\
6 & Rectum (C20) & M & 72 & 32 & pT3N1aM0 & G2 & atorvastatinum \\
7 & Hepatic flexure (C18.3) & F & 65 & 30 & pT3N0M0 & G2 & rosuvastatinum \\
8 & Caecum (C18.1) & M & 67 & 29 & pT2N1aM0 & G2 & atorvastatinum \\
9 & Sigmoid colon (C18.7) & M & 68 & 28 & pT2N0M0 & G2 & atorvastatinum, fenofibratum \\
10 & Rectum (C20) & M & 80 & 33 & pT1N0M0 & G1 & no \\
11 & Rectosigomid junction (C19) & M & 60 & 23 & pT3N1M0 & G2 & no \\
12 & Caecum (C18.1) & F & 84 & 24 & pT4bN1bM1a & G2 & rosuvastatinum \\
13 & Ascending colon (C18.2) & M & 52 & 25 & pT3N0M0 & G2 & no \\
14 & Hepatic flexure (C18.3) & F & 86 & 22 & pT3N0M0 & G2 & rosuvastatinum \\
15 & Descending colon (C18.6) & M & 60 & 30 & pT3N1bM0 & G2 & no \\
16 & Rectosigomid junction (C19) & F & 75 & 23 & pT3N1bM0 & G2 & no \\
17 & Rectosigomid junction (C19) & M & 80 & 22 & pT3N0M0 & G2 & atorvastatinum \\
19 & Caecum (C18.1) & F & 87 & 19 & pT4aN0M0 & G2 & no \\
\hline & Caecum (C18.1) & F & 80 & 26 & pT2N0M0 & G2 & rosuvastatinum \\
\hline
\end{tabular}

room temperature for 30 minutes to allow clotting, and then centrifuged at $3000 \mathrm{xg}$ for 15 minutes at $4^{\circ} \mathrm{C}$. After centrifugation, the sera were stored in aliquots at $-80^{\circ} \mathrm{C}$ until analysis. The protocol of the study was compliant with the Declaration of Helsinki of the World Medical Association and granted approval from the Local Bioethics Committee at the Medical University of Gdansk (protocol no. NKBN/487/2015). Prior to the study, written informed consent was sought from all the subjects. Standard laboratory parameters were determined at the Central Clinical Laboratory, Medical University of Gdansk.

\section{Reagents}

All reagents were purchased from Sigma Aldrich (Poznan, Poland).

\section{Extraction and derivatization of fatty acids}

Total lipids were extracted from tissue and whole serum samples with a chloroform-methanol mixture $(2: 1, v / v)$, as described previously [13]. Lipid extracts were dried by evaporation under a stream of nitrogen. Each sample was hydrolyzed with $1 \mathrm{~mL}$ of $0.5 \mathrm{M} \mathrm{KOH}$ in methanol at $90^{\circ} \mathrm{C}$ for $3 \mathrm{~h}$. The mixture was acidified with $0.2 \mathrm{~mL}$ of $6 \mathrm{M} \mathrm{HCl}$, and then $1 \mathrm{~mL}$ of water was added. Non-esterified FAs were extracted three times with $1 \mathrm{~mL}$ of $n$-hexane and evaporated to dryness under a stream of nitrogen. FA methyl esters (FAMEs) were prepared using $1 \mathrm{~mL}$ of $10 \%$ boron trifluoride-methanol solution ( $90 \mathrm{~min}$ at $55^{\circ} \mathrm{C}$ ). After adding $1 \mathrm{~mL}$ of water to the reaction mixture, FAMEs were extracted three times with $1 \mathrm{~mL}$ of $n$-hexane and the solvent was evaporated.

Gas Chromatography-Mass Spectrometry analysis of fatty acids

FAMEs were analyzed with GC-EI-MS QP-2010 SE (Shimadzu, Japan) and separated on a 30-m 0.25$\mathrm{mm}$ i.d. Rtx-5MS capillary column (film thickness $0.25 \mu \mathrm{m}$ ). Temperature of the column was set at $60-300^{\circ} \mathrm{C}$ $\left(4^{\circ} \mathrm{C} / \mathrm{min}\right)$, with helium as the carrier gas and the column head pressure of $60 \mathrm{kPa}$. 70 -eV electrons were used for FAME ionization, with 19-methylarachidic acid as an internal standard (IS). Full scan mode with mass scan range m/z 45-700 was applied. Accurate identification of FA profile was possible due to the use of reference standards (37 FAME Mix, Sigma-Aldrich) and reference library NIST 2011 including mass spectra of methyl esters for all analyzed FAs. Moreover, the identification of cerotic acid was confirmed using its standard (Sigma-Aldrich). 


\section{Cellular Physiology Cell Physiol Biochem 2017;41:722-730 \begin{tabular}{ll|l} 
and Biochemistry Published onlIne: February 08, 2017 & $\begin{array}{l}\text { (c) } 2017 \text { The Author(s). Published by S. Karger AG, Basel } \\
\text { www.karger.com/cpb }\end{array}$ \\
\hline
\end{tabular}

\section{Analysis of mRNA level}

Total cellular RNA was extracted from frozen tissue with RNeasy Lipid Tissue Mini Kit (Qiagen) according to the manufacturer's protocol. The quantity and quality of extracted RNA were assessed by automated gel electrophoresis (Experion, Bio-Rad). Subsequently, cDNA was synthesized from total RNA using RevertAid First Strand cDNA Synthesis Kit (ThermoScientific), and diluted in RNase-free water (1:25). mRNA levels were determined with real-time PCR, using CFX Connect Real-Time System (Bio-Rad), SensiFAST SYBR NO-ROX Kit (Bioline) and $\beta$-actin/cyclophilin A gene combination as a standard. The primer sequences were as follows: ELOV1 F5'CTG TGG CAC AAC CCT ACC TT3', R5'CTG GGA GATGTG CAG TGA GA3', ELOV3 F5'CCT TGC AAT CTT CAG TAT CCT3', R5'GAT GAT GAA GGC TGT GTC TC3', ELOV6 F5'CAA AGC ACC CGA ACT AGG AG3', R5'TGG TGA TAC CAG TGC AGG AA3'. Amplification of specific transcripts was confirmed on the basis of melting curve profiles and agarose gel electrophoresis of the amplification products.

\section{Statistical analysis}

The significance of intragroup differences (CRC tissue vs. normal colon tissue) was verified with paired Student t-test, and the significance of intergroup differences (CRC patients vs. controls) with two-tailed Student $\mathrm{t}$-test. The differences were considered significant at $\mathrm{p}<0.05$. The results are presented as means \pm standard errors of the mean (SEMs). All statistical calculations were carried out with Sigma Stat software.

\section{Results}

Comparative analysis of FA profiles demonstrated that both CRC specimens and normal colon tissue from cancer patients were predominantly composed of 12- to 26-carbon evenchain FAs, with oleic (18:1), palmitic (16:0) and stearic (18:0) acids being the most abundant. Compared to the specimens of normal colon, FA profile of CRC was characterized by changes in some fatty acid content that are presented in Table 2. However, the most striking changes in cancer tissue were significantly higher contents of 22-, 24- and 26-carbon FAs, both SFAs and MUFAs (Fig. 1).

Since the increased content of very long-chain FAs (VLCFAs) in CRC specimens most likely resulted from enhanced fatty acid elongation, we determined mRNA levels for SFAand MUFA-specific elongases (ELOVLs 1, 3 and 6). While ELOVL3 mRNA levels were below the limit of detection in both CRC specimens and normal colon tissue, the former showed a dramatic, 4- and 9-fold, respectively, increase in ELOVL1 and ELOVL6 mRNA levels (Fig. 2A and B). ELOVL activity can be reflected by 18:0/16:0 elongation index value [14]. As shown on Figure 3A, also the values of this parameter were significantly higher in CRC specimens
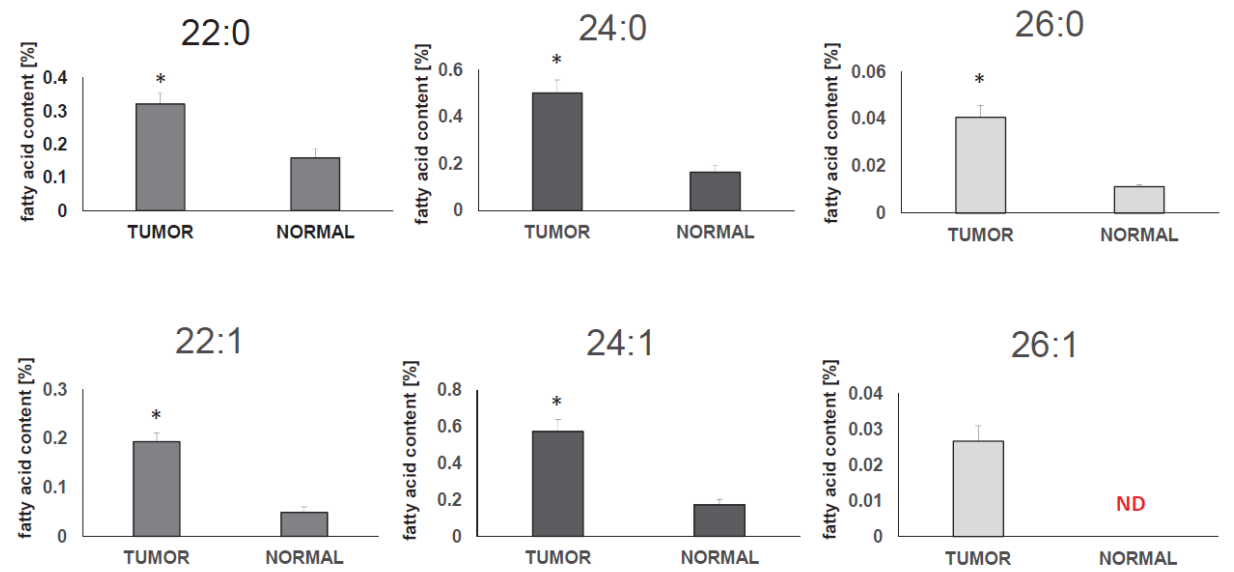

Fig. 1. Contents of very long-chain fatty acids in CRC specimens and normal colon tissue. Data presented as mean \pm SEM. ${ }^{*} \mathrm{p}<0.01$ compared to the controls, ND - not detected. 
Table 2. Fatty acids composition of cancer and normal tissues of CRC patients. * $-\mathrm{p}<0.01$; \# - p < 0.05 ; ND - not detected

\begin{tabular}{|c|c|c|}
\hline & $\begin{array}{l}\text { Cancer tissue } \\
\text { ( } \% \text { of total tissue } \mathrm{FA} \pm \mathrm{SEM} \text { ) }\end{array}$ & $\begin{array}{l}\text { Normal tissue } \\
(\% \text { of total tissue } \mathrm{FA} \pm \mathrm{SEM} \text { ) }\end{array}$ \\
\hline $14: 0$ & $1.04 \pm 0.08^{\circ}$ & $1.79 \pm 0.17$ \\
\hline $16: 0$ & $19.90 \pm 0.28^{\#}$ & $21.09 \pm 0.41$ \\
\hline 18:0 & $13.09 \pm 0.48^{*}$ & $7.78 \pm 0.74$ \\
\hline $20: 0$ & $0.31 \pm 0.03^{\#}$ & $0.21 \pm 0.02$ \\
\hline $22: 0$ & $0.32 \pm 0.03^{*}$ & $0.16 \pm 0.02$ \\
\hline $24: 0$ & $0.50 \pm 0.06^{*}$ & $0.16 \pm 0.03$ \\
\hline $26: 0$ & $0.04 \pm 0.005^{*}$ & $0.01 \pm 0.004$ \\
\hline Other SFA & $1.51 \pm 0.07$ & $1.44 \pm 0.08$ \\
\hline Total SFA & $36.71 \pm 0.48^{\circ}$ & $32.64 \pm 0.85$ \\
\hline $14: 1$ & $0.06 \pm 0.01^{*}$ & $0.20 \pm 0.03$ \\
\hline $16: 1$ & $3.06 \pm 0.24^{*}$ & $4.67 \pm 0.48$ \\
\hline $18: 1$ & $32.03 \pm 1.03^{+}$ & $41.70 \pm 1.49$ \\
\hline $20: 1$ & $0.82 \pm 0.07$ & $0.73 \pm 0.06$ \\
\hline $22: 1$ & $0.19 \pm 0.02^{*}$ & $0.08 \pm 0.01$ \\
\hline $24: 1$ & $0.58 \pm 0.06^{\circ}$ & $0.17 \pm 0.03$ \\
\hline $26: 1$ & $0.03 \pm 0.004$ & ND \\
\hline Other MUFA & $0.26 \pm 0.03$ & $0.26 \pm 0.02$ \\
\hline Total MUFA & $37.03 \pm 1.16^{*}$ & $47.83 \pm 1.86$ \\
\hline $18: 3 n-3$ & $0.08 \pm 0.007$ & $0.06 \pm 0.007$ \\
\hline $20: 5 n-3$ & $0.45 \pm 0.04^{*}$ & $0.25 \pm 0.04$ \\
\hline $22: 6 n-3$ & $1.07 \pm 0.06^{*}$ & $0.47 \pm 0.05$ \\
\hline Other n-3 PUFA & $0.66 \pm 0.04^{*}$ & $0.32 \pm 0.02$ \\
\hline Total n-3 PUFA & $2.26 \pm 0.12^{*}$ & $1.09 \pm 0.10$ \\
\hline $18: 2 n-6$ & $11.00 \pm 0.45$ & $11.73 \pm 0.56$ \\
\hline $20: 4 n-6$ & $6.98 \pm 0.55^{*}$ & $3.33 \pm 0.51$ \\
\hline Other n- 6 PUFA & $2.85 \pm 0.22^{+}$ & $1.20 \pm 0.10$ \\
\hline Total n-6 PUFA & $20.83 \pm 0.64 \#$ & $16.26 \pm 0.99$ \\
\hline
\end{tabular}

Table 3. Fatty acids composition of serum of CRC patients and controls. * $-\mathrm{p}<0.01$; \# - p $<0.05$; a detected in $18 / 18$ patients; $b$ - detected in $5 / 18$ patients; ND - not detected

\begin{tabular}{|c|c|c|}
\hline & $\begin{array}{l}\text { CRC } \\
(\% \text { of total serum } F A \pm S E M)\end{array}$ & $\begin{array}{l}\text { CONTROL } \\
\text { ( } \% \text { of total serum } F A \pm \text { SEM) }\end{array}$ \\
\hline $14: 0$ & $0.80 \pm 0.06^{\#}$ & $0.37 \pm 0.09$ \\
\hline $16: 0$ & $23.92 \pm 0.35$ & $23.36 \pm 0.52$ \\
\hline 18:0 & $6.24 \pm 0.13^{\#}$ & $7.32 \pm 0.17$ \\
\hline $20: 0$ & $0.06 \pm 0.004$ & $0.06 \pm 0.004$ \\
\hline $22: 0$ & $0.15 \pm 0.007^{\#}$ & $0.12 \pm 0.03$ \\
\hline $24: 0$ & $0.12 \pm 0.007$ & $0.12 \pm 0.008$ \\
\hline $26: 0$ & $<0.01-0.01^{a}$ & ND \\
\hline Other SFA & $0.96 \pm 0.08$ & $1.10 \pm 0.06$ \\
\hline Total SFA & $30.41 \pm 2.00$ & $33.29 \pm 0.58$ \\
\hline $14: 1$ & $0.04 \pm 0.003$ & $0.06 \pm 0.03$ \\
\hline $16: 1$ & $2.90 \pm 0.18$ & $3.09 \pm 0.25$ \\
\hline $18: 1$ & $28.39 \pm 0.62^{*}$ & $25.79 \pm 0.86$ \\
\hline $20: 1$ & $0.15 \pm 0.01$ & $0.17 \pm 0.01$ \\
\hline $22: 1$ & $0.05 \pm 0.003$ & $0.04 \pm 0.004$ \\
\hline $24: 1$ & $0.22 \pm 0.02$ & $0.22 \pm 0.03$ \\
\hline $26: 1$ & $<0.01 \mathrm{~b}$ & ND \\
\hline Other MUFA & $0.16 \pm 0.01$ & $0.18 \pm 0.01$ \\
\hline Total MUFA & $30.04 \pm 2.06$ & $29.56 \pm 1.0$ \\
\hline $18: 3 n-3$ & $0.17 \pm 0.01^{\#}$ & $0.30 \pm 0.02$ \\
\hline $20: 5 n-3$ & $0.64 \pm 0.09^{*}$ & $1.13 \pm 0.18$ \\
\hline $22: 6 n-3$ & $1.09 \pm 0.07$ & $1.78 \pm 0.12$ \\
\hline Other n-3 PUFA & $0.32 \pm 0.02^{*}$ & $0.38 \pm 0.007$ \\
\hline Total n-3 PUFA & $2.25 \pm 0.16^{*}$ & $2.98 \pm 0.30$ \\
\hline $18: 2 n-6$ & $22.72 \pm 0.86$ & $25.46 \pm 1.09$ \\
\hline $20: 4 n-6$ & $5.27 \pm 0.25$ & $5.53 \pm 0.23$ \\
\hline Other n-6 PUFA & $1.18 \pm 0.11$ & $1.32 \pm 0.04$ \\
\hline Total n-6 PUFA & $29.24 \pm 0.86^{*}$ & $32.31 \pm 1.16$ \\
\hline
\end{tabular}

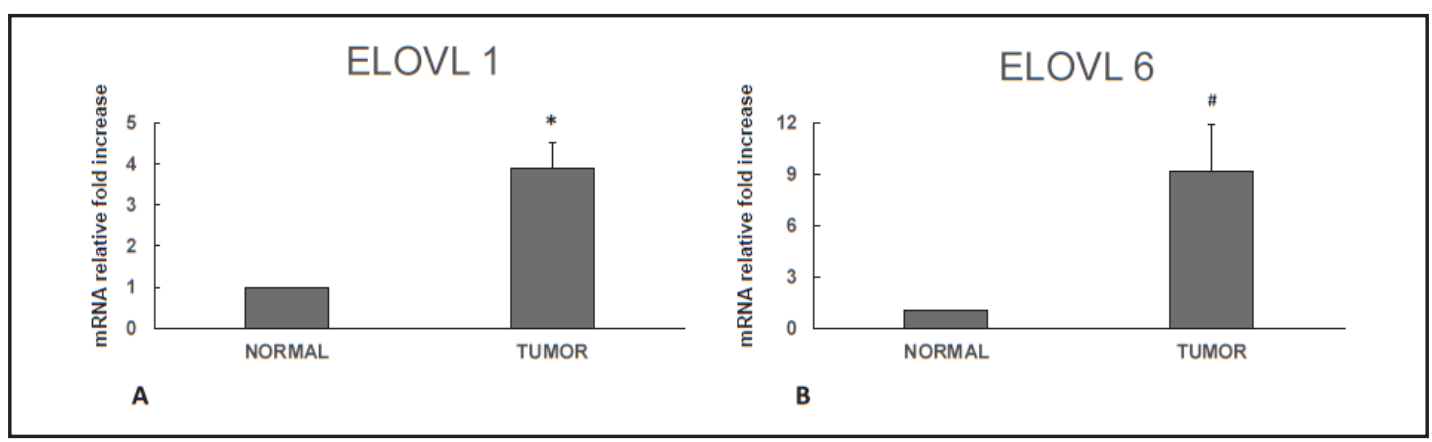

Fig. 2. ELOVL1 (A) and ELOVL6 (B) mRNA levels, in CRC specimens and normal colon tissue. Data presented as mean \pm SEM. ${ }^{*} \mathrm{p}<0.01, \#-\mathrm{p}<0.05$ compared to the controls.

than in normal colon. Similarly 22-26:0/20:0 elongation index values (sum of 22:0, 24:0 and 26:0 divided by 20:0), that also reflects ELOVL activity, were higher in cancer tissue (Fig. 3B).

Finally, we verified if the overexpression of ELOVLs and the increase in VLCFA content of CRC specimens were reflected in fatty acid profiles in sera of cancer patients. In the serum of CRC patients we found slightly decreased levels of total n-3 and n-6 PUFA as well as changes in some specific SFA and MUFA content as compared to healthy controls (Table 3 ). However, the most interesting finding was the presence of small amounts of cerotic acid (hexacosanoic acid; 26:0) in sera of all individuals with CRC but in none of the controls (Table 


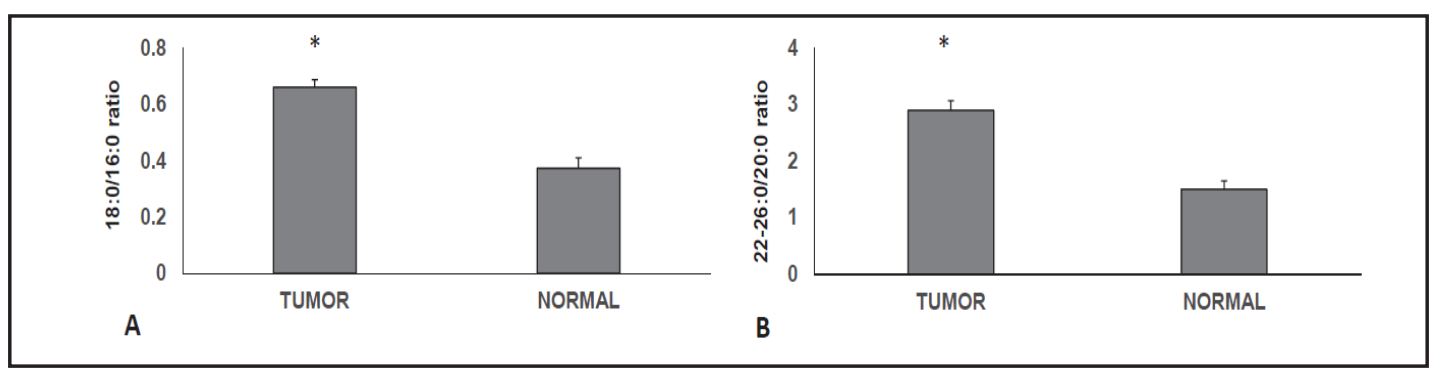

Fig. 3. 18:0/16:0 (A) and 22-26:0/20:0 (B) elongation index values in CRC specimens and normal colon tissue. Data presented as mean \pm SEM. $* p<0.01$ compared to the controls.

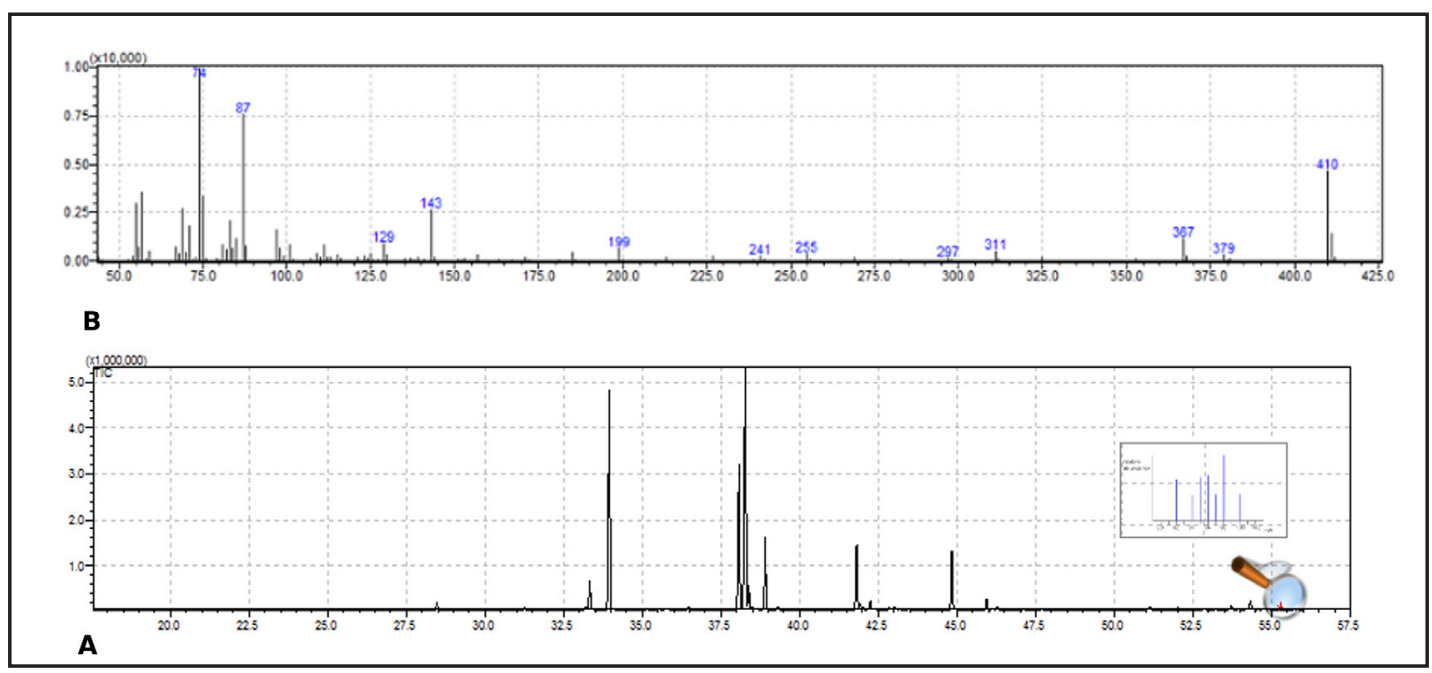

Fig. 4. Chromatogram (A) and the mass spectrum (B) of cerotic acid from serum of CRC patient.

3 ). The serum content of cerotic acid constituted up to $0.01 \%$ of total FA, that is equivalent to concentration $270 \mu \mathrm{g} / \mathrm{L}$. The lowest concentration that enables to detect the ions of cerotic acid by our method is $1 \mu \mathrm{g} / \mathrm{L}$. The mass spectrum of cerotic acid found in serum of one of our CRC patients is presented on Fig. 4.

\section{Discussion}

Our study demonstrated a significant enhancement of FA elongation (which can be also referred to as hyper-elongation) in CRC specimens. Previous studies documented other alterations of lipid metabolism in colon tumors. Keshk et al. [15] showed that the expression and activity of FASN gene increase with the progression of colon cancer. Also other authors reported enhanced expression of FASN $[16,17]$, and found an association between this parameter and survival of CRC patients [16]. Furthermore, inhibition of FASN turned out to be associated with decreased proliferation rate of cancer cells [18]. Based on these results it can be hypothesized that enhanced synthesis of FAs may provide substrates for ELOVLs, which results in hyper-elongation of fatty acids, as observed in CRC specimens in our study. Delta-9 stearoyl-CoA desaturase (SCD1) is another enzyme overexpressed in colon tumors. SCD1 is involved in synthesis of FAs, specifically in conversion of SFAs to MUFAs [19]. Noticeably, we found elevated levels of very-long chain SFAs and MUFAs in our material (Fig. 1). We did not find any statistically significant correlation between TNM stage, patients BMI and the content of VLCFAs in cancer tissue. The statins intake also did not influence their levels in cancer nor in normal tissues. However, according to small sample size in this study 


\section{Cellular Physiology Cell Physiol Biochem 2017;41:722-730 \begin{tabular}{ll|l} 
DOI: 10.1159/000458431 & O 2017 The Author(s). Published by S. Karger AG, Basel \\
and Biochemistry
\end{tabular} \\ Mika et al.: Hyper-Elongation in Colorectal Cancer}

further research on a larger group of CRC patients is needed to elucidate the association between the content of VLCFAs in cancer tissue and TNM stage, BMI and statin intake. While the results of previous studies point to the overexpression of enzymes involved in FA synthesis in colon cancer tissue, our study adds to this evidence, demonstrating for the first time the phenomenon of FA hyper-elongation in CRC specimens. Enhanced elongation of FAs has been already documented in other malignancies. Recently, Marien et al. [12] revealed overexpression of ELOVL6 in SCC, and demonstrated that inhibition of this enzyme decreased proliferation rate of SCC cell lines in vitro and their growth in an in vivo mouse model. These results suggest that ELOVL6 may play a critical role in the development and metabolism of cancer cells. Overexpression of ELOVL6 was also reported in NASH-associated hepatocellular carcinoma $[20,21]$. Another elongase, ELOVL1, was shown to be overexpressed in breast cancer tissue [22]. The underlying mechanism of FA hyper-elongation in CRC specimens is still to be understood. According to Marien et al. [12], VLCFAs may play an important role in maintaining the structure and thickness of plasma membranes, and contribute considerably to the topology and/or activity of the membrane proteins.

Constant increase in the incidence of CRC justifies research on novel specific markers of this malignancy. Although our study was relatively small, we demonstrated the presence of cerotic acid in serum samples from all examined CRC patients and in none of the controls. Elevated levels of cerotic acid were previously reported in other diseases. Adachi et al. [23] found higher levels of cerotic acid and hexacosenoic acid (26:1) in erythrocyte membranes in alcoholic patients. According to these authors, this was a result of alcohol-induced interruption of peroxisomal beta-oxidation, a process involved in VLCFA metabolism [23]. Elevated serum levels of cerotic acid were also observed in X-linked adrenoleukodystrophy, an inherited disorder of peroxisomal metabolism characterized by deficient $\beta$-oxidation of saturated VLCFAs [24], as well as in other diseases associated with peroxisomal disorders [25]. A link between elevated concentration of cerotic acid and increased risk for metabolic syndrome or cardiovascular disorders has been postulated as well [26, 27]. Recently, cerotic acid was identified as a blood lipid biomarker of dementia [28]. Nevertheless, none of the previous studies documented an association between the presence of this FA and carcinogenesis. Moreover, our findings suggest that cerotic acid found in sera of CRC patients is a product of FA hyper-elongation in tumor tissue, rather than a marker of peroxisomal metabolic disorders. This hypothesis is also supported by the results of a recent study conducted by Pickens et al. [29] who found that higher ELOVL6 activity estimates in blood are associated with increased risk of colon adenoma. All this evidence points to serum cerotic acid as a strong candidate for specific metabolic marker of CRC. 22- and 24-carbon FAs may also be released from cancer tissue into circulation, but since they are present in sera of control subjects (Table 3 ), these small amounts from cancer tissue likely did not influence significantly their serum concentrations in CRC patients.

One potential limitation of our study is its small sample size. Nevertheless, our hereby presented findings seem to be reliable and consistent, since CRC specimens showed a dramatic increase in both VLCFA content and ELOVL gene expression, and cerotic acid was found solely in all cancer patients' sera.

\section{Conclusion}

CRC specimens show enhanced FA elongation, and serum cerotic acid seems to be a strong candidate for metabolic marker of this malignancy. However, it is still unclear if this FA is specific for CRC, or can be also found in other malignancies. Therefore, further research on a larger group of CRC patients is needed to elucidate if serum cerotic acid can be used as a diagnostic marker of CRC and perhaps also as a marker of its progression. 


\section{Cellular Physiology Cell Physiol Biochem 2017;41:722-730 and Biochemistry \begin{tabular}{l|l} 
DOI: 10.1159/000458431 & (c) 2017 The Author(s). Published by S. Karger AG, Basel \\
www.karger.com/cpb
\end{tabular} \\ Mika et al.: Hyper-Elongation in Colorectal Cancer}

\section{Abbreviations}

BMI, (body mass index); CRC, (colorectal cancer); FA, (fatty acids; ELOVLs, elongases; FASN, fatty acid synthase; MUFAs, monounsaturated fatty acids; PUFAs, polyunsaturated fatty acids; SCD1, Delta-9 stearoyl-CoA desaturase; SFAs, saturated fatty acids; VLCFAs, very long chain fatty acids

\section{Acknowledgment}

This study was supported by the Ministry of Science and Higher Education of the Republic of Poland, from the quality-promoting subsidy under the Leading National Research Centre (KNOW) program for the years 2012-2017, the Ministry of Science and Higher Education of the Republic of Poland grant no. DS 530-8615-D592-15, and Medical University of Gdansk (grants no. ST-40, ST-89).

\section{Disclosure Statement}

The authors have declared no conflict of interest.

\section{References}

1 Zhang W, Zou C, Pan L, Xu Y, Qi W, Ma G, Hou Y, Jiang P: MicroRNA-140-5p inhibits the progression of colorectal cancer by targeting VEGFA. Cell Physiol Biochem 2015;37:1123-1133.

2 Xu K, Liu X, Mao X, Xue L, Wang R, Chen L, Chu X: MicroRNA-149 suppresses colorectal cancer cell migration and invasion by directly targeting forkhead box transcription factor FOXM1. Cell Physiol Biochem 2015;35:499-515.

3 Marley AR, Nan H: Epidemiology of colorectal cancer. Int J Mol Epidemiol Genet 2016;7:105-114.

4 Jia H, Wang Z: Telomere length as a prognostic factor for overall survival in colorectal cancer patients. Cell Physiol Biochem 2016;38:122-128.

-5 Yan G, Li L, Zhu B, Li Y: Lipidome in colorectal cancer. Oncotarget 2016 Mar 7;7:33429-33439.

6 Swierczynski J, Hebanowska A, Sledzinski T: Role of abnormal lipid metabolism in development, progression, diagnosis and therapy of pancreatic cancer. World J Gastroenterol 2014 Mar 7;20:2279-2303.

7 Zaytseva YY, Harris JW, Mitov MI, Kim JT, Butterfield DA, Lee EY, Weiss HL, Gao T, Evers BM: Increased expression of fatty acid synthase provides a survival advantage to colorectal cancer cells via upregulation of cellular respiration. Oncotarget 2015;6:18891-18904.

8 Cruz PMR, Mo H, Mcconathy WJ, Sabnis N, Lacko AG: The role of cholesterol metabolism and cholesterol transport in carcinogenesis : a review of scientific findings , relevant to future cancer therapeutics. Front Pharmacol 2013;4:1-7.

-9 Carracedo A: Cancer metabolism: fatty acid oxidation in the limelight. Nat Rev Cancer 2013;13:227-232.

$\checkmark 10$ Jakobsson A, Westerberg R, Jacobsson A: Fatty acid elongases in mammals: Their regulation and roles in metabolism. Prog Lipid Res 2006;45:237-249.

11 Matsuzaka T, Shimano H: Elovl6: A new player in fatty acid metabolism and insulin sensitivity. J Mol Med 2009;87:379-384.

12 Marien E, Meister M, Muley T, Gomez Del Pulgar T, Derua R, Spraggins JM, Van de Plas R, Vanderhoydonc F, Machiels J, Binda MM, Dehairs J, Willette-Brown J, Hu Y, Dienemann H, Thomas M, Schnabel PA, Caprioli RM, Lacal JC, Waelkens E, Swinnen JV: Phospholipid profiling identifies acyl chain elongation as a ubiquitous trait and potential target for the treatment of lung squamous cell carcinoma. Oncotarget 2016;7:12582-12597.

13 Sledzinski T, Mika A, Stepnowski P, Proczko-Markuszewska M, Kaska L, Stefaniak T, Swierczynski J: Identification of cyclopropaneoctanoic acid 2-hexyl in human adipose tissue and serum. Lipids 2013;48:839-848. 


\section{Cellular Physiology Cell Physiol Biochem 2017;41:722-730

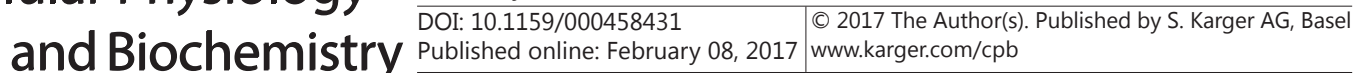 \\ Mika et al.: Hyper-Elongation in Colorectal Cancer}

- 14 Mika A, Kaska L, Korczynska J, Mirowska A, Stepnowski P, Proczko M, Ratnicki_Sklucki K, Goyke E, Sledzinski T: Visceral and subcutaneous adipose tissue stearoyl-CoA desaturase-1 mRNA levels and fatty acid desaturation index positively correlate with BMI in morbidly obese women. Eur J Lipid Sci Technol 2015;117:926-932.

15 Keshk, Walaa, Elkhadrawy 0: Fatty acid synthase / oxidized low-density lipoprotein as metabolic oncogenes linking obesity to colon cancer via NF-kappa B in Egyptians. Med Oncol 2014;31:192.

-16 Ogino S, Nosho K, Meyerhardt JA, Kirkner GJ, Chan AT, Kawasaki T, Giovannucci EL, Loda M, Fuchs CS: Cohort study of fatty acid synthase expression and patient survival in colon cancer. J Clin Oncol 2008;26:5713-5720.

17 Uddin S, Hussain AR, Ahmed M, Abubaker J, Al-Sanea N, Abduljabbar A, Ashari LH, Alhomoud S, Al-Dayel F, Bavi P, Al-Kuraya KS: High prevalence of fatty acid synthase expression in colorectal cancers in Middle Eastern patients and its potential role as a therapeutic target. Am J Gastroenterol 2009;104:1790-1801.

18 Kuhajda FP, Pizer ES, Li JN, Mani NS, Frehywot GL, Townsend CA: Synthesis and antitumor activity of an inhibitor of fatty acid synthase. PNAS 2000;97:3450-3454.

19 Li J, Ding SF, Habib NA, Fermor BF, Wood CB, Gilmour RS: Partial characterization of a cDNA for human stearoyl-CoA desaturase and changes in its mRNA expression in some normal and malignant tissues. Int J Cancer 1994;57:348-352.

20 Kessler SM, Simon Y, Gemperlein K, Gianmoena K: Fatty acid elongation in non-alcoholic steatohepatitis and hepatocellular carcinoma. Int J Mol Sci 2014;15:5762-5773.

-21 Muir K, Hazim A, He Y, Peyressatre M, Kim D, Song X: Proteomic and lipidomic signatures of lipid metabolism in NASH-associated hepatocellular carcinoma. Mol Cell Pathobiol 2013;73:4722-4732.

-22 Hilvo M, Denkert C, Lehtinen L, Müller B, Brockmüller S, Seppünen-Laakso T, Budczies J, Bucher E, Yetukuri L, Castillo S, Berg E, Nygren H, Sysi-Aho M, Griffin JL, Fiehn O, Loibl S, Richter-Ehrenstein C, Radke C, Hyötyläinen T, Kallioniemi O, Iljin K, Oresic M: Novel theranostic opportunities offered by characterization of altered membrane lipid metabolism in breast cancer progression. Cancer Res 2011;71:3236-3245.

23 Adachi J, Miwa A, Ueno Y, Asano M, Naito T, Imamichi H, Tatsuno Y: Abnormality of very long-chain fatty acids of erythrocyte membrane in alcoholic patients. Alcohol Clin Exp Res 1998;22:103-107.

-24 Deon M, Garcia MP, Sitta A, Barschak AG, Coelho DM, Giugliani R, Vargas CR: Hexacosanoic and docosanoic acids plasma levels in patients with cerebral childhood and asymptomatic X-linked adrenoleukodystrophy: Lorenzo's oil effect. Metab Brain Dis 2008;23:43-49.

-25 Schutgens RBH, Bouman IW, Nijenhuis AA, Wanders JA, Marielle EJ: Profiles of very-long-chain fatty acids in plasma, fibroblasts, and blood cells in Zeliweger syndrome, X-linked adrenoleukodystrophy, and rhizomelic chondrodysplasia punctata. Clin Chem 1993;39:1632-1637.

26 Kume A, Miyazaki T, Kitamura Y, Oshida K: High levels of saturated very long-chain fatty acid (hexacosanoic acid; C26:0) in whole blood are associated with metabolic syndrome in Japanese men. Diabetes Res Clin Pr 2008;80:259-264.

27 Okahashi A, Okada T, Saito E, Miyashita M, Kuromori Y, Iwata F, Hara M, Mugishima H, Kitamura Y, Shimizu T: Concentrations of very long-chain fatty acid in whole blood are associated with cardiovascular risk factors in children. Clin Chim Acta 2009;401:141-143.

-28 Zarrouk A, Riedinger J-M, Ahmed SH, Hammami S, Chaabane W, Debbabi M, Ben Ammou S, Rouaud O, Frih M, Lizard G, Hammami M: Fatty acid profiles in demented patients: identification of hexacosanoic acid (C26:0) as a blood lipid biomarker of dementia. J Alzheimers Dis 2014;44:1349-1359.

-29 Pickens CA, Lane-Elliot A, Comstock SS, Fenton JI: Altered saturated and monounsaturated plasma phospholipid fatty acid profiles in adult males with colon adenomas. Cancer Epidemiol Biomarkers Prev 2016;25:498-507. 